\title{
ALBEDO-RAINFALL FEEDBACK OVER INDIAN MONSOON REGION USING LONG TERM OBSERVATIONS BETWEEN 1981 TO 2000
}

\author{
B.K. Bhattacharya ${ }^{a}$, *K.R.Gunjal ${ }^{\mathrm{a}}$, S. Panigrahy ${ }^{\mathrm{a}}$ and J.S. Parihar ${ }^{\mathrm{b}}$

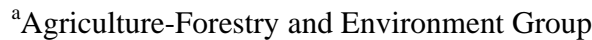 \\ ${ }^{\mathrm{b}}$ Remote Sensing Applications Area (RESA) \\ Space Applications Centre (ISRO), Ahmedabad 380015, India \\ *Email: keshavgunjal@sac.isro.gov.in
}

KEYWORDS: Land Surface Albedo, Satellite, Rainfall, Climate Change, India

\begin{abstract}
:
Albedo determines radiation balance of land (soil-canopy complex) surface and influence boundary layer structure of the atmosphere. Accurate surface albedo determination is important for weather forecasting, climate projection and ecosystem modelling. Albedo-rainfall feedback relationship has not been studied so far using observations on spatial scale over Indian monsoon region due to lack of consistent, systematic and simultaneous long-term measurements of both. The present study used tenday satellite (e.g. NOAA) based Pathfinder AVHRR Land (PAL) datasets between 1981 and 2000 over India $\left(68-100^{\circ} \mathrm{E}, 5-40^{\circ} \mathrm{N}\right)$ at $8 \mathrm{~km}$. Land surface albedo was computed using linear transformation of red and near infrared (NIR) surface reflectances. The cloud effects were removed using a smoothening filter with harmonic analysis applied to time series data in each year. The monthly, annual and long term means were computed from ten-day reconstructed albedo. The mean and coefficient of variation (CV) of surface albedo over seventeen years, averaged over Indian land region, were found to show a decreasing ( 0.15 to 0.14 and 39 to 34\%, respectively) trend between 1981 and 2000. Further analysis showed that, among all the land use patterns, the inter-annual variation of albedo of Himalayan snow cover showed a prominent reducing trend $(0.42-0.35)$. This could be due to increase in snow melting period and snow melt area. The annual rainfall measured at IMD (India Meteorological Department) gauging stations, interpolated and averaged over $35 \times 33$ grids $\left(1^{\circ} \times 1^{\circ}\right)$ also show declining trend (1300 to $\left.1150 \mathrm{~mm}\right)$ during this period, suggesting strong coupling between snow albedo and rainfall. A strong inverse exponential relation (correlation coefficient $r=0.95, n=100$ ) was found between annual rainfall and annual albedo over seven rainfall zones.
\end{abstract}

\section{INTRODUCTION}

Satellite remote sensing data in optical, thermal infrared and microwave bands with synoptic observations from space platform are ideal to study long term changes on earth surface that really took place or are happening at variety of spatial scales (local, regional, continental) as compared to model simulations driven by many uncertain boundary conditions. However, a long term database of satellite observations call for (i) continuity of satellite sensors with similar spectral bands with accurate radiometric calibration, spatial resolution and time of overpasses (ii) similar retrieval algorithm (iii) systematic data storage on the same projection over the years. The remote sensing observations from past, current and future suite of large swath (moderate to coarser resolution) polar orbiting and geostationary satellite sensors can be utilized to study long term change. It is well known that different land surface types can affect climate in a variety of ways, perhaps the most important being their effects on surface albedo, normalized difference vegetation index (NDVI) and land surface temperature (LST). A change from grassland or crops to forest will tend to decrease albedo and increase aerodynamic roughness length. In contrary, the clearing of forests and their replacement by cropland or pastures increase the surface albedo and thus decrease the absorption of incoming shortwave radiation. Increase in albedo should decrease net radiation and warm the surface, while the increase in roughness should enhance the turbulent exchange of energy and thereby tend to cool. In the physical climate system, albedo determines the radiation balance of the surface and affects the boundary-layer structure of the atmosphere. In ecological system, albedo controls the microclimate conditions of plant canopies and their radiation absorption, which in turn, affect ecosystem physical, physiological and biogeochemical processes such as energy balance, evapotranspiration, photosynthesis and respiration. Several studies have shown that surface albedo has a negative effect on moisture flux convergences and rainfall. Desertification results generally into droughts by a positive feedback between land and atmosphere caused by high surface albedo. This has been demonstrated through simulation by several workers (Charney et al., 1975; Chervin, 1979; Dirmeyer and Shukla, 1996). Very little work has been done over Indian monsoon region in this direction to generate realistic seasonal climatic surface albedo and its fundamental coupling with rainfall or surface wetness. The present study was carried out with the following objectives:

1. To generate least cloud contaminated long term surface albedo and its long term trend over Indian landmass using surface reflectance data in red and near-infrared (NIR) bands of NOAA AVHRR Pathfinder between 1981-2001 
2. To study the coupling between diagnostic albedo from satellite observations and gridded rainfall from in situ measurements

\section{STUDY REGION AND DATASETS}

The present study used NOAA PAL data on Indian subsets (68$100^{\circ} \mathrm{E}, 5-40^{\circ} \mathrm{N}$ ) from Asian continental datasets between January 1981 and December 2000. The pathfinder Advanced Very High resolution Radiometer (AVHRR) Land (PAL) datasets are terrestrial global data, mapped at 8-km equal area projection, produced from archived data from 5 channel AVHRR sensor on board NOAA satellite, namely NOAA-7, NOAA-9, NOAA-11, NOAA-12 and NOAA-14. Ten-day NDVI were made as maximum value composites (MVC) from consequtive ten days starting from $1^{\text {st }}$ day of a month. There are three such dekadal (10-day) composites in a given month. The third dekads contain eight day or nine day (for leap year) composite in the month of February and eleven day composite for the months of January, March, May, July, August, October and December. All other composite products including channel reflectances and brightness temperatures were generated picking up pixel values of different variables from those days of corresponding maximum NDVI.

\section{METHODOLOGY}

\subsection{Computation of surface albedo}

Land surface albedo (A) was computed using linear transformation from red and NIR narrowband reflectance's given by Valiente et al. (1995).The coefficients were generated with exhaustive radiative transfer simulations for different scenario of atmospheric conditions, surface types and albedo using relative spectral response (RSR) of NOAA AVHRR.

$$
\mathrm{A}=0.035+0.545 \mathrm{CH} 1+0.32 \mathrm{CH} 2
$$

This model was later validated with in situ measurements.

\subsection{Harmonic analysis and reconstruction of albedo com- posites}

The opetical data from satellite sensors are often perturbed by the presence of clouds and dense haze. The presence cloud increases the reflectivity in red and NIR bands as compared to land surfaces. Time series composite satellite data generally show internal spikes due to persistent cloudy conditions when cloud could not be removed while compositing. These datasets need to be temporally smoothed before analysis. This study used the HANTS (Harmonic Analysis of Time Series) algorithm (For detailed algorithm, see Menenti et al., 1993; Roerink et al., 2000). The HANTS algorithm was devised with the application to the time series of NDVI images in mind. The presence of Clouds always increases the pixel albedo though compositing removes the short-term cloud effects. In HANTS a curve fitting is applied iteratively, i.e. first a least square curve is computed based on all data points and the next observations are compared to the curve (Julien et al., 2006). Albedo that are clearly above the curve are candidates for rejection due to cloud cover, and the points that have the greatest positive deviation from the curve therefore are removed first. Next a new curve is computed based on the remaining points and process is repeated. Pronounced outliers are removed by assigning a weight of zero to them, and a new curve is computed. This iteration eventually leads to a smooth curve that approaches the lower envelope over the data points. In this way cloudy observations have been removed and the amplitudes and phases computed are much more reliable than those based on a straightforward FFT (Fast Fourier Transform). This algorithm was run over 36 decadal albedo datasets in each year between 1981 and 2001. The frequency, Fit Error Tolerance (FET), Degree of Over Determinedness (DOD) was kept as 5, 3 and 5, respectively. A temporally consistent albedo has been reconstructed in this study from ten-day albedo from PAL surface reflectance over the years.

\subsection{Preparation of Zonal Rainfall from Annual Gridded Databases}

The ASCII file of daily gridded rainfall data were read through IDL (Interactive Data Language) routines. The daily gridded $\left(1^{\circ}\right.$ $\mathrm{x} 1^{\circ}$ ) rainfall were generated using Shepard interpolation (Rajeevan et al, 2006) through measured rainfall data from 1803 IMD (India Meteorological Department) stations in India. The daily rainfall data were further summed up to produce annual total. India has clear demarcation of seven (7) rainfall zones defined by IMD as given below :

1. Zone I : $<200 \mathrm{~mm}$ per year

2. Zone II : $200 \mathrm{~mm}$ to $400 \mathrm{~mm}$ per year

3. Zone III: $400 \mathrm{~mm}$ to $800 \mathrm{~mm}$ per year

4. Zone IV: $800 \mathrm{~mm}$ to $1000 \mathrm{~mm}$ per year

5. Zone $\mathrm{V}: 1000 \mathrm{~mm}$ to $2000 \mathrm{~mm}$ per year

6. Zone VI: $2000 \mathrm{~mm}$ to $4000 \mathrm{~mm}$ per year

7. Zone VII: $>4000 \mathrm{~mm}$ per year

The boundaries of rainfall zones were digitized to generate seven zonal polygons with geographic latitude / longitude projection. The annual total gridded rainfall averaged over each zone was extracted for all the years between 1982 and 2000 to investigate the albedo-rainfall feedback on spatial context. The overall methodology is shown schematically in Figure 1.

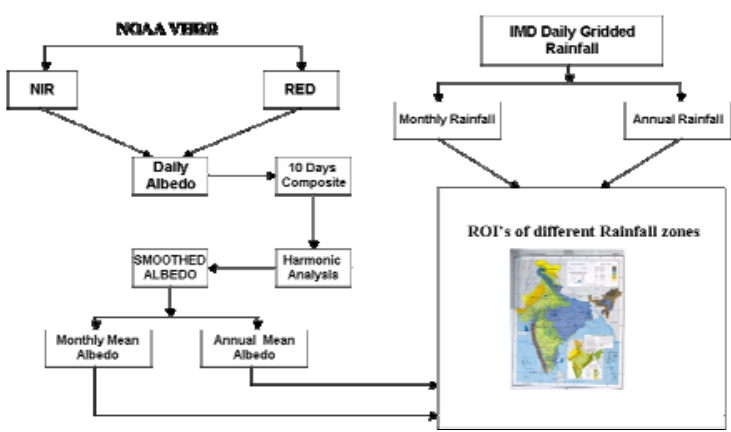

Figure 1. Overall Flow of Data Processing 


\section{RESULTS AND DISCUSSION}

\subsection{Effect of Temporal Smoothening and Climatic Land Surface Albedo}

Typical examples of temporally smoothened albedo over different land surface categories such as: desert, agriculture and forest for year 2000 are shown in Figure 2. The spikes due to clouds and other significant atmospheric noises were removed through the smoothening technique. The monthly climatic albedo was also computed from three dekadal albedo in a given month over twenty years. The climatic albedo varied between 0.07 over forest to as high as 0.9 over snow. Among all the land cover types, the highest seasonal dynamics was found over snow between 0.15 in July-August to 0.9 in February-March. Among forest, desert and agriculture, the latter showed a seasonality between 0.1 to 0.2 with the lowest in August corresponding to peak growth. The forest land use showed lowest seasonality. The albedo seasonality averaged over different cover types are exemplified in Figure 3 from climatic monthly means. The spatial distribution of monthly climatic albedo is shown in Figure 4. These monthly climatic albedos are useful inputs to climate models such as GCM and RCM. The monthly surface albedos can be used as ground reference albedo in connection with TOA (Top-of-atmosphere) albedo from broad VIS band in Indian geostationary sensors to derive the integrated atmospheric optical depth and turbidity over Indian landmass. Till now, climate modelers in India have relied upon the average or single albedo value instead of spatially and temporally varying climatic albedo over Indian sub-continent to specify as input to climate model for predicting intra seasonal variability of Indian south-west monsoon rainfall. This is the first exhaustive attempt to generate temporally consistent spatial albedo having higher grid resolution (8 $\mathrm{km} \mathrm{X}$ $8 \mathrm{~km}$ ) than climate model grid resolution (For RCM : $30 \mathrm{~km} \mathrm{x}$ $30 \mathrm{~km}$; For GCM : $100 \mathrm{~km} \mathrm{x} \mathrm{100km)} \mathrm{from} \mathrm{synoptic} \mathrm{and}$ diagnostic observations from satellite sensor.
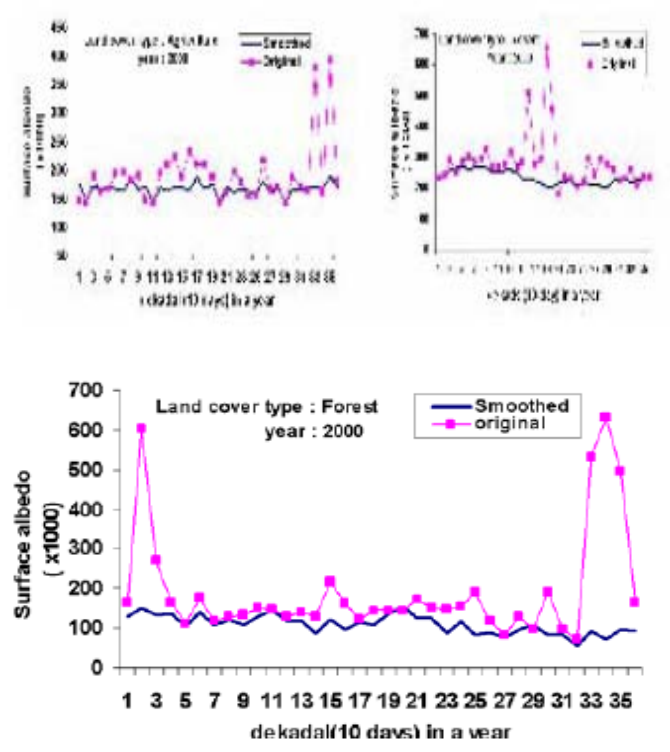

Figure 2. Examples of Temporal Smoothening of Surface Albedo Over Different Land Cover Types

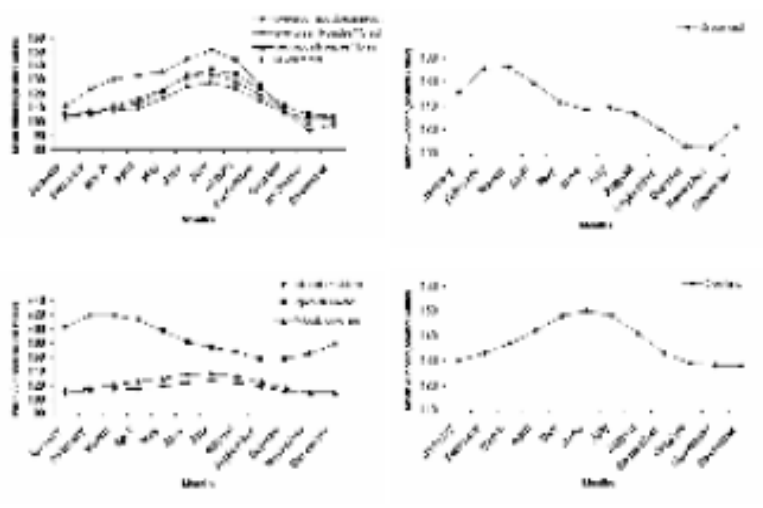

Figure 3. Seasonal Dynamics of Surface Albedo Over Different Land Use Classes

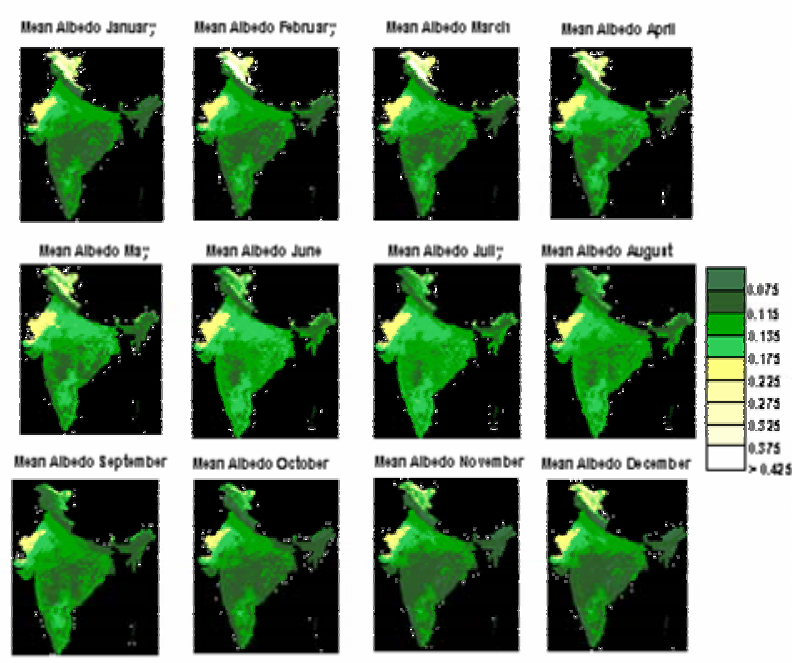

Figure 4. Examples of Monthly Surface Albedo Over Indian Landmass

\subsection{Trend analysis of surface albedo over Indian landmass}

The climatic mean surface albedo from seventeen years, averaged over Indian land surface, was found to show a decreasing trend (Figure 5) between 1982 and 2000. There was

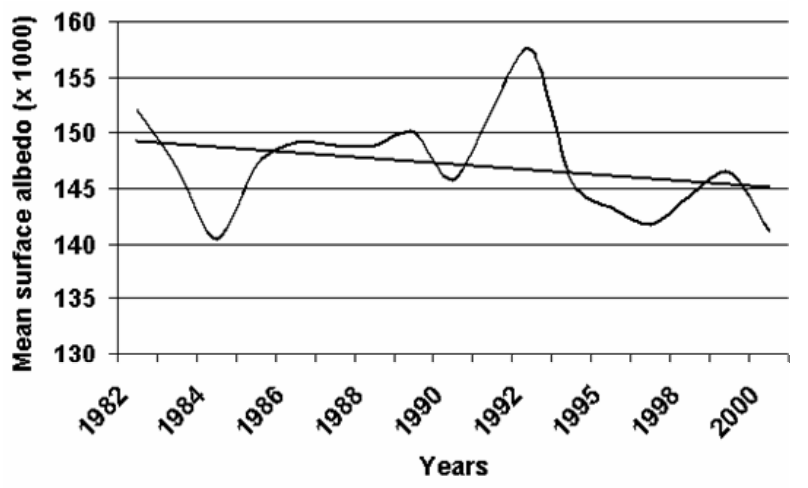



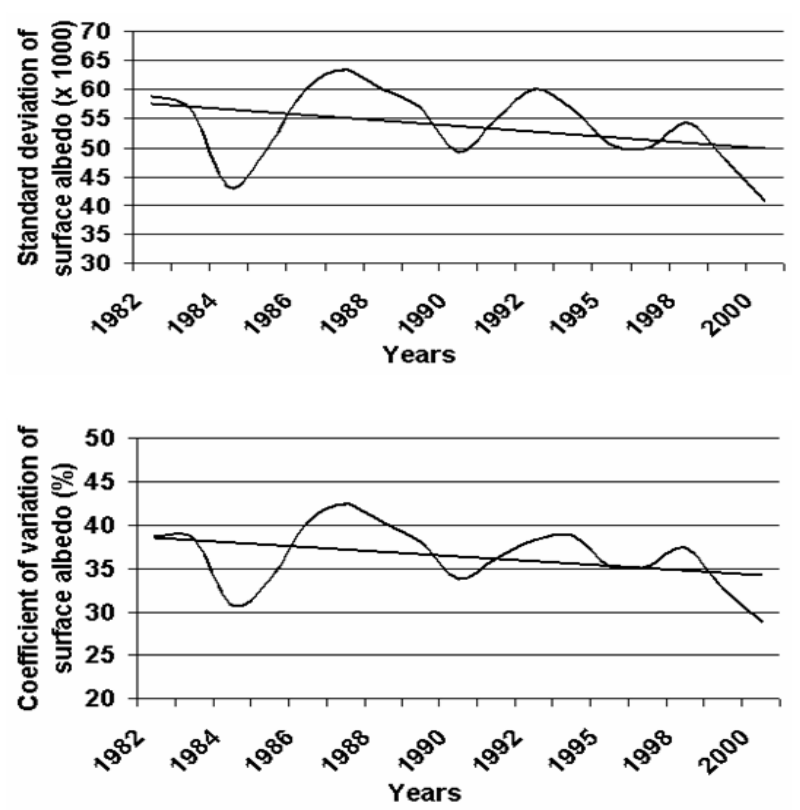

Figure 5. Long Term Trend in Annual Land Surface Albedo of India

a sharp decline of standard deviation and coefficient of variation (CV) to the tune of 0.06 to 0.04 and 60 to 40 percent.The surface albedo generally decreases with increase in vegetation amount or surface wetness. Among all the land use categories, the crop lands, deciduous forest and snow are most dynamic on annual scale. The first two are dependent on soil wetness and later is dependent on annual temperature cycle causing snow melt in summer-monsoon months leading to lowering of albedo and freezing during winter months resulting into increase in albedo.The increasing wetness from more irrigated areas brought under canal command and recent technological shift towards in situ field water conservation instead of more drainage may cause the lowering trend of albedo.

\subsection{Albedo-Rainfall Coupling}

The anthropogenic change in land use pattern and land surface albedo generally have strong influence on micro and mesoclimatic conditions. Large scale deforestation causes warming and increase in atmospheric buoyancy thereby hinder to raindrops to fall on surface. The cooling due to transpiration from presence of forest or plantations facilitates precipitation. The coupling between surface albedo and rainfall at spatial scale need to be investigated in order to characterize albedorainfall relationship. The plot of annual mean albedo averaged over different rainfall zones and IMD gridded annual rainfall from observations over those zones was made. Here, the gridded rainfall over snow was not considered because the fifty years' average annual rainfall from the extrapolation of single station observation does not match with the existing climatic rainfall zone map. There was strong inverse exponential relation with correlation $(r=0.95)$ between satellite observed albedo and observed gridded rainfall (Figure 6). Similar relations were found out in West Africa between albedo and rainfall by several workers (Charney, 1977, Fuller et al 2002., Govaerts et al, 2008). This is the first time such an attempt has been made in India. This relationship is highly sensitive to albedo errors. A small error in albedo may translate into large error in predicted rainfall. The albedo anomaly is expected to be coupled with rainfall or land (canopy + soil) surface wetness. This study established the potential use of albedo anomaly for in-season monitoring of land surface state.

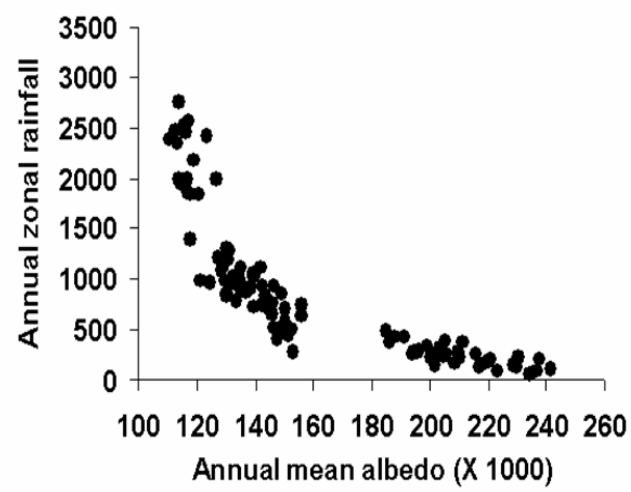

Figure 6. Relationship Between Zonal Rainfall and Albedo

\section{CONCLUSION}

This is the first study in India to study the long term albedo changes in different land use systems as well as albedo-rainfall feedback relation using satellite data and measured rainfall on regional scale. The most significant finding is that there is declining trend in albedo over Indian landmass. This could be both due to (i) higher vegetation growth in no-snow areas and (ii) increase in snow melting period and increase in snow-melt area. Further analysis is needed to correlate this past albedo trend with the current trend during 2001 to 2010 over different land uses.

\section{ACKNOWLEDGEMENTS}

The authors are grateful to Dr. R.R. Navalgund, Director, Space Applications Centre for his encouragement and support. The study is a part of ISRO-GBP project "Energy and Mass Exchange in Vegetative Systems”. The authors are also thankful to India Meteorological Department for providing gridded rainfall data. The support and encouragement provided by Dr. N. K. Patel, Head, CMD/AFEG/RESA, Space Applications Centre are gratefully acknowledged.

\section{REFERENCES}

Charney, J., 1977. A comparative study of the effect of albedo change on drought in semi arid regions. Journal of the atmospheric sciences, 36, pp. 1366-1385.

Chervin, R., M., 1979, Response on the NCAR general circulation model to changed land surface albedo. Report of the JOC study conference on climate models, vol.1, GARP pub., ser. No. 22, WMO, 563-581. 
Dirmeyer, P., A. and Shukla, J., 1993. Observational and modelling studies of the influence of soil moisture anomalies on atmospheric circulation. NATO series J.,VOL., springer Verlag, 1-23.

Fuller, D.O. and Ottke, C., 2002. Land cover, rainfall and land surface albedo in West Africa. Climate Change, 54, pp. 181204.

Govaerts, Y. and Lattanzio, A., 2008. Estimation of surface albedo increase during the eighties Sahel drought from meteosat observations. Global and planetary change, 64 (3-4), pp. 139145.

Julien, Y., Sobrino, J.A., Verhoef, W., 2006. Changes in land surface temperatures and NDVI values over Europe between 1982 and 1999. Remote Sensing of Environment, 103(1), pp. 43-55.

Menenti, M., Azzali, S., Verhoef, W., Van Swol, R., 1993. Mapping agro-ecological zones and time lag in vegetation growth by means of Fourier analysis of time series of NDVI images. Advances in Space Research, 5, 233-237.

Rajeevan, M., Bhate, J., Kale, J.D., Lal, B., 2006. High resolution daily gridded rainfall data for the Indian region : Analysis of active and break monsoon spells. Current Science, 91(3), pp. 296 - 306

Roerink, G.J., Menenti, M., Verhoef, W., 2000. Reconstructing cloudfree NDVI composites using Fourier analysis of time series. International Journal of Remote Sensing, 21(9), 19111917.

Valiente, J., A., Nunez, M., Lopez, E., Moreno, J., 1995. Narrow band to broad band conversion for meteosat visible channel and broadband albedo using both AVHRR-1 and 2 channels. International Journal of Remote Sensing, 16(6), pp. 1147-1166. 